\title{
STRATEGY, STRATEGIC MANAGEMENT ACCOUNTING AND PERFORMANCE: A CONFIGURATIONAL ANALYSIS
}

\begin{abstract}
Purpose

The purpose of this study is to investigate the effectiveness of different configurational archetypes of strategy and strategic management accounting and to appraise how management accounting's horizontal and vertical alignment with strategy can facilitate performance.

Design/methodology/approach

The study deploys a holistic configurational approach to examine the relationship between strategy, strategic management accounting, and performance. Configurations are derived empirically using an inductive approach from a sample of 109 manufacturing companies.

Findings

The observed configurations (i.e. 'analytics', 'blue-chips', 'first movers', 'domestic protectors', 'laggards and socialism relics') constitute varying levels of performance and varying degrees of fit. Support is provided for the equifinality proposition that different strategic and structural alternatives are associated with similar performance levels. Equivocal support is provided for the configurational proposition that internally consistent configurations are associated with higher performance.
\end{abstract}

\section{Research limitations/implications}

The variables examined do not fully capture the complexity of pertinent configurations. Limitations revolve around application of the cluster analytical technique and its reliance on researcher judgement.

\section{Practical implications}

The study's most important message concerns the manner in which it highlights the fallibility of assuming a singular relationship between strategic choices and management accounting system design. While prior research has tended to offer fragmented and unidirectional management accounting prescriptions, we raise the notion of how key variables can interact to create an effective organization.

\section{Originality/value}

The study breaks new ground by showing that multiple designs of strategy and strategic management accounting may be equally effective in a particular context. This finding challenges much traditional contingency based modelling in management accounting.

\section{Keywords}

Strategy, strategic management accounting, performance, configurations, equifinality

\section{Paper type}

Research paper 


\section{STRATEGY, STRATEGIC MANAGEMENT ACCOUNTING AND PERFORMANCE: A CONFIGURATIONAL ANALYSIS}

\section{Introduction}

The relationship between strategy, management accounting based control systems and performance has commanded significant attention in the accounting and management research domains (see Langfield-Smith [1997] and Tucker et al. [2009] for a review). The quantum of this research provides support for the view that management accounting plays a pivotal role in the development and execution of business strategy (Chenhall and Langfield-Smith, 1998). The accumulated body of evidence also suggests that tailoring an organisation's management accounting control system to its strategy may result in enhanced performance.

Most empirical work in this area assumes a contingency approach (Chenhall, 2003; Langfield-Smith, 1997). The popularity of this research paradigm underscores its importance and vitality (Gerdin and Greve, 2004), despite some noted criticisms (see Fiss, 2007; Gerdin and Greve, 2008; Gresov and Drazin, 1997). One major shortcoming concerns the predictive capacity of the contingency approach. Contingency theory assumes the concept of unifinality which concerns the expectation that there is a single structural design that best fits a given strategy and hence results in highest performance (Gerdin and Greve, 2004; Gresov and Drazin, 1997). Advocates of the equifinality concept (Doty et al., 1993; Fiss, 2007; Gresov and Drazin, 1997; Marlin et al., 2007; Payne, 2006) question this view by promoting the possibility of multiple, equally effective, structures that are supportive of a given strategy. A second concern revolves around the fragmented nature of contingency models that results from methodological limitations (Gerdin and Greve, 2008). Typically, these studies deploy causal models where one variable, or set of variables, is used as an antecedent of another variable or, set of variables (Fiss, 2007; Luft and Shields, 2003). This methodology is problematic for two reasons. First, it signifies an approach that views variables as competing in explaining outcomes, rather than showing how variables can combine to create outcomes (Fiss, 2007). Second, it implies that relationships are unidirectional, instead of acknowledging that not only may strategy affect strategic management accounting systems, strategic management accounting systems may also shape strategy (Simons, 1987; 1994).

Contrary to contingency theory, which incorporates the concepts of unifinality, competition and causation, configurational theory is based on concepts of equifinality, combination and reciprocity. The configurational paradigm promotes viewing organizations as clusters of interconnected structures and practices (Ferguson and Ketchen, 1999; Fiss, 2007; Short et al., 2008), where effectiveness can be attributed to internal consistency amongst the patterns of relevant contextual, structural and strategic factors (Doty et al., 1993; Ketchen et al., 1993). It aspires to provide predictional insight with respect to which firm configurations will be successful under what sets of circumstances (Ketchen et al., 1997; Short et al., 2008). 
Important motivation for the study reported herein derives from Payne (2006) and Short et al. (2008) who call for more explicit examination of equifinality in different contexts. This is one of the first studies to adopt a configurational perspective with respect to strategic choices, strategic management accounting systems, and performance. The study provides two main basic contributions. First, it extends our appreciation of the strategy-strategic management accounting relationship beyond simple bivariate associations, by examining the validity of equifinality and configurational propositions in the strategic management accounting context. Second, it provides evidence that similar levels of performance can be achieved using different strategic and structural alternatives.

The remainder of the paper is organized as follows. In the next section, the concepts of strategy and strategic management accounting are discussed and configurational fit propositions are developed. Then the research method is described, followed by an outline of the findings. The discussion section provides an overview of the most salient issues arising from the study.

\section{Literary context and proposition development}

The focus of this study is on business strategy, which concerns how firms compete in an industry or market (Olson et al., 2005; Simons, 1987; Slater and Olson, 2001). There is a consensus that strategic priorities should be supported by appropriate management accounting systems in order to facilitate performance (Anderson and Lanen, 1999; Cadez and Guilding, 2008; Carr et al, 2010; Chenhall and Langfield-Smith, 1998; Hammad et al, 2010; Trkman, 2010). As business strategies become increasingly complicated, simply exploring for relationships between management accounting system characteristics and particular strategic archetypes appears somewhat limited and prosaic. Many researchers believe that a more meaningful analysis can be undertaken by investigating several dimensions of strategy (e.g., DeSarbo et al., 2005; Ittner and Larcker, 2001; Ketchen et al., 1993; Olson et al., 2005). In this study we appraise three dimensions: (1) strategic type (prospector/defender), (2) degree to which strategy is deliberately formulated, and (3) degree of market orientation. The Miles and Snow (1978) prospector/defender typology was adopted due to its innate parsimony and industry-independent nature (Desarbo et al., 2005; Shortell and Zajac, 1990) and also because it has been widely adopted and validated in prior research. The inclusion of the latter two dimensions was motivated by the importance accorded to the dimensions by strategy researchers, a development that has not been mirrored in accounting research.

Strategic management accounting (SMA) is a relatively recently conceived management accounting subset that focuses on accounting's facilitation of strategic decisions and strategic management processes (Bhimani and Langfield-Smith, 2007; Hoque, 2003; Ittner and Larcker, 2001; Roslender and Hart, 2003; Yi and Tayles, 2009). While research interest in strategic management accounting is growing (Langfield-Smith, 2008), there is still limited consensus with respect to what constitutes SMA. In this study we adopt Cadez and Guilding's (2008) SMA conceptualization which concerns two distinct facets of strategically oriented accounting. These are: (1) the adoption of 
strategically-oriented management accounting techniques and (2) accountant's participation in strategic management processes.

\subsection{Strategy dimensions}

Strategy typologies constitute profiles of different strategic postures that emphasize integrative components of different strategies. The Miles and Snow (1978) typology comprises four strategic types (prospector, defender, analyzer, and reactor) that constitute holistic configurations of organizational factors. The typology's longevity can be attributed to its innate parsimony (Desarbo et al., 2005; Shortell and Zajac, 1990), however some recent empirical studies question the typology's merit (see Desarbo et al., 2005 ; 2006). One point of contention concerns the relationships among the four types. While Miles and Snow describe them as unique types, considerable evidence suggests that three of the types lie on a spectrum, with defenders and prospectors at opposite ends and analyzers located between these two extremes (Doty et al., 1993; Shortell and Zajac, 1990). Further, Olson et al. (2005) feel that the typology suffers from an internally focussed orientation and propose a hybrid model that represents a synthesis with Porter's low cost vs differentiation typology distinguishing between low cost defenders and differentiated defenders.

Most documented conceptions of strategy imply that it is the outcome of a deliberate stream of decisions (Langfield-Smith, 1997). Mintzberg and Waters (1985) and Mintzberg (1987) counter this view by stressing the amibiguous and evolutionary nature of strategy in many organisations. They see strategy more as a pattern or stream of actions, regardless of whether these actions are intended. In practice, pure deliberate and pure emergent strategies are rarely in evidence, as most firms fall somewhere between the two extremes (Mintzberg and Waters, 1985).

Market orientation is intrinsic to much modern management and strategy (Dobni and Luffman, 2003; Narver and Slater, 1990). The market orientation philosophy concerns the view that all company activities should be focussed on satisfying customer needs (Hult et al., 2005; Zelbst et al., 2010). While initially a marketing concept, market orientation tends now to be viewed in broad terms as a cultural factor affecting the dayto-day thinking and actions across all functional areas (Dobni and Luffman, 2003).

\subsection{Strategic management accounting dimensions}

With respect to the first facet of SMA, strategically-oriented management accounting techniques can be distinguished from conventional management accounting techniques by their environmental (outward-looking) or long-term (forward-looking) orientations (Guilding et al., 2000; Hoque, 2003). Cadez and Guilding (2008) identified 16 such techniques and consolidated them to five underlying SMA themes: (1) strategic costing, (2) strategic planning, control and performance management, (3) strategic decision making, (4) competitor accounting, and (5) customer accounting.

The second facet of SMA, accountant participation in strategic management processes, has more of a sociological tenor. In contemporary competitive settings, organisations are 
increasingly focussed on providing value to customers (Dobni and Luffman, 2003). This is triggering a flattening of organizational structures through the integration of heightened customer-focussed activities across the value-chain (Green et al, 2011; Trkman et al., 2010). In "horizontal organizations" decisions are made by crossfunctional management teams, including management accountants (Aver and Cadez, 2009; Naranjo-Gil and Hartmann, 2007). Unlike their conventional counterparts, strategic management accountants are no longer seen merely as information providers, they now represent active players in the strategic management process ( $\mathrm{Yi}$ and Tayles, 2009).

\subsection{Strategy and strategic management accounting system configurations}

Organizational configurations are clusters of organizations that share a common profile with respect to key characteristics such as strategy, structure and decision processes (Ferguson and Ketchen, 1999; Ketchen et al., 1993; Short et al., 2008). Configurational analysis is founded on the view that organizations can be clustered around key characteristics (Fiss, 2007). Configurational theory can be distinguished from universalistic and contingency theories by its more holistic principle of inquiry and also its assumption of equifinality (Delery and Doty, 1996; Doty and Glick, 1994). In general, the theory is concerned with how a pattern of multiple independent variables (e.g., strategy and SMA) relate to a dependant variable (e.g., performance), rather than how individual independent variables relate to a dependant variable (Fiss, 2007).

Much configurational research focuses on the link between clusters of similar organizations and performance (Ferguson and Ketchen, 1999; Ketchen et al., 1997; Short et al., 2008). Equifinality is in evidence when organizations employing different strategic and structural approaches achieve equivalent levels of performance (Doty et al., 1993; Gresov and Drazin, 1997; Marlin et al., 2007; Payne, 2006). Gresov and Drazin (1997) refer to three forms of equifinality: suboptimal, trade-off, and configurational. In this study, the most complex configurational form of equifinality is assumed. This situation is characterized by the availability of multiple strategic alternatives and relatively unconstrained structural options in meeting strategic demands (Marlin et al., 2007). This assumption is predicated on there being no single best way of organizing (Gresov and Drazin, 1997).

\section{Equifinality proposition:}

Different strategic and SMA system alternatives can lead to similar organizational performance levels.

Configurational theory asserts that performance is attributed to internal consistency amongst the patterns of relevant structural and strategic factors (Doty et al., 1993; Ketchen et al., 1993). Little interest has been directed, however, to substantiating the internal consistency concept (Malmi and Brown, 2008). Delery and Doty (1996) argue that organizational performance is facilitated when an SMA system manifests both horizontal and vertical fit. 
Horizontal fit concerns internal consistency of an organization's practices and procedures. Given that SMA techniques exhibit outward and long-term (strategic) orientations, an equivalent degree of usage across the SMA dimensions would seem to imply internal consistency. This appears consistent with Cadez and Guilding's (2008) conceptualization of SMA usage as a single, albeit multidimensional, construct. Further, high accountant involvement in strategy processes appears consistent with high SMA technique usage, as greater involvement in strategy can be expected to inculcate accountants with an appreciation of information needs posed by strategic management (Abernethy and Bouwens, 2005).

Vertical fit refers to the congruence of SMA and firm strategy. Partial bivariate relationships between strategy dimensions and management accounting system designs have been investigated in prior studies. These suggest that high SMA technique usage levels and greater involvement of accountants in strategy processes are more congruent with a dynamic prospector type strategy (Chenhall, 2003; Guilding, 1999), deliberate decisions (Bhimani and Langfield-Smith, 2007; Simons, 1987), and higher market orientation (Guilding and McManus, 2002; Hult et al., 2005).

The level of complexity in examining fit in a configurational setting rises far beyond the capacity of bivariate analysis, however (Doty and Glick, 1994). To illustrate this, imagine a very simple model with just three variables: strategy type, market orientation and SMA usage. Evidence accumulated in bivariate studies suggests that SMA usage is positively associated with prospector strategy and high market orientation. Now imagine that a particular company is pursuing a defender strategy and is highly market oriented. In such a situation, the demands placed on SMA system design by multiple contingencies may conflict (Gerdin, 2005). Any attempt to tailor SMA system design to strategic context has to grapple with the trade-off issue. that is bound to preclude fit between all factors being achieved concomitantly (Gerdin, 2005; Gresov, 1989).

\section{Configurational fit proposition:}

Higher horizontal and vertical internal consistency of strategy-SMA system configurations is associated with higher organizational performance.

\section{Research method}

The study has deployed the widely-used empirical/inductive approach to defining configurations. Following Ketchen et al. (1993), we rely on clustering procedures applied to a comprehensive set of variables to derive configurations. Cluster analysis is an acknowledged technique for distilling groups of cases that exhibit similar characteristics (Ferligoj and Batagelj, 1992; Fiss, 2007; Ketchen and Shook, 1996).

The data analysis procedure to examine the posited propositions comprises three steps. First, configurations are derived by means of cluster analysis. Second, performance scores are calculated and appraised for individual clusters/configurations. Third, an interpretive appraisal of the horizontal and vertical fit is undertaken.

\subsection{Data collection}


Ketchen et al. (1997) recommend focusing configurational research on a single industry, hence we have restricted our investigation to manufacturing companies. A questionnaire survey was used to collect the data. The initial sample comprised the 300 largest Slovenian manufacturing companies. Following the exclusion of companies with inaccurate or incomplete mailing addresses, the questionnaire was mailed to 254 companies. Each company was contacted by phone in order to identify the most suitable person to complete the survey. In most cases, the individual identified carried the title 'Chief Controller', however other titles used were 'Chief Accountant' and 'Chief Financial Officer'. Each subject was sent a copy of the questionnaire, a covering letter explaining the study's purpose and a glossary of terms used. The first mailing yielded 71 usable responses and the second mailing provided a further 38 usable responses. This signified a $42.9 \%$ overall usable response rate. Table 1 classifies the companies that comprise the data set.

Table 1. Industrial affiliation of sampled companies

\begin{tabular}{lcc}
\hline \multicolumn{1}{c}{ Industry } & $\begin{array}{c}\text { Number of } \\
\text { firms }\end{array}$ & $\begin{array}{c}\text { Percentage } \\
\text { of sample }\end{array}$ \\
\hline Food, beverages and tobacco & 18 & 16.5 \\
Textile, apparel, leather, wood and furniture & 30 & 27.5 \\
Chemicals, plastics, non-metallic products & 19 & 17.4 \\
Metal products & 14 & 12.8 \\
Machinery, electric, electronics and automotive & 28 & 25.7 \\
Total & 109 & 100.0 \\
\hline
\end{tabular}

Kolmogorov-Smirnoff tests of differences between responses provided in the first and last $25 \%$ of the questionnaires returned were conducted. These tests revealed no significant differences $(p<0.05)$ in the data provided by these sub-groups for any of the survey questions, thus signifying little concern for non-response bias.

\subsection{Variable measurement}

\section{Prospector/defender business strategy}

Shortell and Zajac's (1990) measure was used. This measure gauges organizational strategic orientation on a seven-point scale ranging from the defender to prospector archetype.

\section{Deliberate vs emergent strategy}

An original measure was developed, as no prior operationalisation of this dimension of strategy has been found in the literature. Drawing on Mintzberg's (1987) terminology, three statements were developed to measure degree of strategy deliberation: (1) "In our company, the strategic decision-makers usually think through everything in advance of strategic action" (2) "In our company, strategic intentions are seldom realized with little or no deviation", and (3) "In our company, strategic action usually develops in the absence of strategic intention". A seven-point scale was provided, ranging from "1" (strongly disagree) to "7" (strongly agree), next to each statement. 


\section{Market orientation}

Market orientation was gauged on a seven-point scale using the four-item instrument developed by Guilding and McManus (2002).

SMA usage

SMA usage was gauged using two instruments. For four SMA dimensions, the Guilding et al. (2000) measures were used. These are: (1) strategic costing (comprising 5 techniques), (2) strategic planning and control (2 techniques), (3) strategic decision making ( 2 techniques), and (4) competitor accounting (3 techniques). For the customer accounting dimension ( 3 techniques) the Guilding and McManus (2002) measure was used. To aid interpretation, a glossary providing a description of all the SMA techniques referred to in the questionnaire was provided to respondents.

\section{Accountant's participation in strategic decision making}

A five-item instrument on a seven-point scale that derives from Wooldridge and Floyd's (1990) measure of middle management's strategic decision making involvement was used.

\section{Performance}

Performance was gauged using an adapted version of Hoque and James' (2000) measure. Three dimensions of performance were appraised: (1) return on investment, (2) (3) development of new products, and (3) market share. For each dimension, respondents indicated their company's relative performance on a scale ranging from " 1 " (below average) to "7" (above average).

\subsection{Data analysis}

The study has analysed configurations of three strategic choices and two dimensions of SMA, a total of five constructs. SMA usage has been specified as a five-dimensional construct, however, hence the total cluster analysis was based on nine constructs. All multi-item constructs were represented as composite items calculated as an average of the original items (see Table 2) to reduce measurement error (Ittner and Larcker, 2001). Before the composite items were calculated, their reliability and validity were investigated. Two items (i.e. quality costing, which is within the SMA strategic costing dimension; and valuation of customers as assets, which is within the SMA customer accounting dimension) were dropped from further analysis due to their low internal reliability. The remaining items have all been included in the computation of composite items.

Table 2. Descriptive statistics for explored constructs

\begin{tabular}{lccc}
\hline & Mean & $\begin{array}{c}\text { Standard } \\
\text { deviation }\end{array}$ & $\begin{array}{c}\text { Crombach } \\
\text { alpha }\end{array}$ \\
\hline Strategy & & 1.25 & N/A \\
Prospector/defender strategy & 4.66 & 1.14 & 0.73 \\
Degree of strategy deliberation & 5.23 & 1.02 & 0.87 \\
Market orientation & 5.24 & & \\
SMA system & & &
\end{tabular}




\begin{tabular}{llll} 
Accountant's participation in strategy & 4.96 & 1.27 & 0.91 \\
Strategic costing usage & 3.74 & 1.27 & 0.74 \\
Planning and control usage & 4.27 & 1.29 & 0.73 \\
Strategic decision making usage & 4.29 & 1.60 & 0.86 \\
Competitor accounting usage & 4.01 & 1.27 & 0.77 \\
Customer accounting usage & 3.48 & 1.59 & 0.78 \\
Performance variables & & & \\
Return of investment & 4.43 & 1.30 & N/A \\
Development of new products & 4.50 & 1.29 & N/A \\
Market share & 4.66 & 1.06 & N/A \\
\hline
\end{tabular}

Prior to cluster analysis, to facilitate interpretation, all variables were standardized. In order to derive clusters of companies that are similar within groups and remote between groups a widely-recommended two step cluster analysis procedure was applied (Hair et al., 1998; Ketchen and Shook, 1996; Ketchen et al., 1993). The objective of the first step is to determine a meaningful number of clusters (Jung et al., 2003). Following Ketchen and Shook (1996), several hierarchical cluster procedures were deployed. Visual inspection of the dendrograms produced, together with the agglomeration coefficients suggested a convergence towards a 6 cluster solution. In the second stage, the non-hierarchical K-means cluster procedure was employed. The K-means procedure is an iterative partitioning method that initially divides observations into a predetermined number of clusters (Slater and Olson, 2001). Based on the hierarchical procedure undertaken, the predetermined number of clusters was set at 6 . Contrary to hierarchical methods, non-hierarchical methods allow multiple data analysis iterations, thus the final solution optimizes within-cluster homogeneity and between-cluster heterogeneity (Ketchen and Shook, 1996).

A validation examination of the derived clusters was also undertaken. Without validation, one cannot be confident that a meaningful and useful set of clusters has been derived (Ketchen and Shook, 1996), as they may represent mere statistical artefacts (Ketchen et al., 1993). First, to face validate the derived clusters, we developed a description and label for each of the clusters (shown in the next section). This step signifies the synthesising of quantitative findings into qualitative gestalts (Slater and Olson, 2001). Second, to appraise external validity (Ketchen and Shook, 1996), we examined whether the members of each cluster exhibit characteristics that correspond to the discerned configurations (Ketchen et al., 1993). The analysis was conducted by an industry expert who, in general terms, expressed satisfaction with the derived groups of companies and their labels/descriptions. Third, an appraisal of criterion-validity was pursued by following an approach devised by Ketchen and Shook (1996). This involves undertaking an examination for significant associations with external variables that are theoretically related to the clusters, but were not used in defining clusters (Ketchen and Shook, 1996). In our case, the external variables were three performance measures, i.e. return on investment, development of new products, and market share.

\section{Cluster analysis findings}

Table 3 presents the variable standardized mean scores for the companies classified into the six clusters. In this table, the clusters are presented in descending ROI sequence (the 
cluster presented in the first data column has the highest ROI, and the cluster in the extreme right hand column has the lowest ROI). 
Table 3. Cluster based cross-tabulation of mean standardised variable scores

\begin{tabular}{|c|c|c|c|c|c|c|}
\hline Cluster & 1 & 2 & 3 & 4 & 5 & 6 \\
\hline Cluster name & Analytics & $\begin{array}{l}\text { Blue- } \\
\text { chips }\end{array}$ & $\begin{array}{c}\text { First } \\
\text { movers }\end{array}$ & $\begin{array}{l}\text { Domestic } \\
\text { protectors }\end{array}$ & Laggards & $\begin{array}{l}\text { Socialism } \\
\text { relics }\end{array}$ \\
\hline Number in cluster & 24 & 25 & 7 & 13 & 31 & 9 \\
\hline \multicolumn{7}{|l|}{ Strategy } \\
\hline Strategy prospector/defender & 0.20 & 0.33 & 1.86 & -0.34 & -0.40 & -1.06 \\
\hline Degree of strategy deliberation & 0.48 & 0.46 & -0.33 & -1.45 & 0.27 & -1.15 \\
\hline Market orientation & 0.23 & 0.47 & 0.88 & -0.03 & -0.22 & -1.81 \\
\hline \multicolumn{7}{|l|}{ SMA system } \\
\hline Accountant's strategy participation & 0.82 & -0.45 & 0.82 & 0.36 & -0.37 & -0.83 \\
\hline Strategic costing usage & 0.83 & -0.02 & 1.13 & 0.33 & -0.69 & -1.15 \\
\hline Planning and control usage & 0.44 & 0.44 & 1.31 & 0.13 & -0.57 & -1.65 \\
\hline Strategic decision making usage & 0.84 & 0.04 & 0.62 & -0.01 & -0.41 & -1.40 \\
\hline Competitor accounting usage & 0.02 & 0.63 & 1.18 & -0.15 & -0.46 & -0.94 \\
\hline Customer accounting usage & 0.43 & 0.45 & 1.36 & -0.28 & -0.62 & -0.93 \\
\hline \multicolumn{7}{|l|}{ Performance variables ${ }^{\mathrm{a}}$} \\
\hline Return of investment & 0.25 & 0.22 & 0.11 & 0.02 & -0.13 & -0.93 \\
\hline Development of new products & 0.22 & 0.38 & 0.82 & -0.09 & -0.46 & -0.56 \\
\hline Market share & 0.16 & 0.21 & 0.45 & 0.39 & -0.29 & -0.93 \\
\hline
\end{tabular}

${ }^{\mathrm{a}}$ Not used in determining clusters.

Note: F-tests for all clustering variables were statistically significant at 0.01 probability level. Significant F-tests indicate that statistical differences exist for individual variables across clusters (Hair et al., 1998).

\subsection{Cluster descriptions - face validation}

Cluster 1 companies follow an analyzer strategy with a deliberate strategy formulation approach and a mediocre market orientation. Accountant's participation in strategy is highest for this cluster. The usage of SMA techniques is relatively high, with the exception of competitor accounting, which appears to be deployed to no more than an average degree. Companies within this grouping do not exhibit a strong explicit strategic priority; hence we label this cluster 'analytics'.

Organizations in cluster 2 are somewhat prospector oriented, take a deliberate approach to strategy formulation and have a relatively high market orientation. Cluster 2 accountants' participation in strategy is relatively low, and SMA technique usage ranges from fairly high (i.e. competitor accounting) to average (i.e. strategic costing). An investigation of the composition of this cluster has revealed that it mostly comprises large well-established Slovenian companies. Accordingly, this cluster has been labelled 'blue-chips'.

The third cluster is the smallest. The distinctive characteristics of this cluster include a very high prospector orientation, a very high market orientation, high accountant participation in strategy and high SMA usage. Due to this cluster's high propensity for seeking new product/market opportunities, we have labelled it 'first movers'.

Cluster 4 companies have a defender strategy orientation, a highly emergent philosophy on strategy formulation and their accountants' participation in strategy is fairly high. They have an average degree of market orientation and use SMA techniques to an 
average extent. Their relatively high usage of SMA strategic costing appears consistent with a defender strategic posture (Slater and Olson, 2001). An examination of the composition of this cluster reveals companies that are predominantly focused on the domestic market. Hence we label them 'domestic protectors'.

The final two clusters comprise companies with similar characteristics. Cluster 5 businesses are defender oriented, their strategy formulation is somewhat deliberate and they have a relatively low market orientation. Accountants' participation in strategy is low and there is low application of SMA techniques. This largest group appears to resemble the reactors archetype proposed by Miles and Snow (1978), hence we label it 'laggards'. With the exception of strategy deliberation, cluster 6 companies appear to manifest the characteristics of the laggard cluster, but to a greater extent. An inspection of the companies that populate this sixth cluster reveals that a large proportion have had trouble adapting to the market economy, hence we label them 'socialism relics'.

The performance indicators, which were measured on three distinct dimensions, provide criterion-validity for these gestalts. As one would expect, a strong relationship between a prospector orientation and performance with respect to new products is in evidence. Interestingly, with the exception of the socialism relics cluster, there is limited variability on the ROI dimension of performance. The distinct strategies of being a 'first mover' or a 'protector' both appear to be valid approaches to the market, as they rank highest with respect to market share. Overall, it appears that the first three clusters can be viewed as relatively successful, as they score above the mean on all of the three performance dimensions appraised. The laggards and socialism relics groups appear as poor performers, as they score lowly across all three performance dimensions appraised.

\subsection{Appraisal of the equifinality and SMA configurational fit propositions}

Performance scores across the clusters provide some support for the equifinality proposition that different strategic and SMA system alternatives lead to similar levels of performance. The analytics and blue-chips clusters, for example, are very similar across the performance dimensions, yet quite different with respect to their strategic choices and SMA systems. A similar conclusion can be drawn by comparing first movers and domestic protectors. From Table 3, it can be seen that first movers and domestic protectors are very similar in terms of financial and market share dimensions of performance, yet completely different with respect to their strategy and SMA systems.

An appraisal of the configurational fit proposition is more complex. The analytics group features high accountant participation in strategy and high SMA adoption rates (with the exception of competitor accounting dimension), this suggests relatively high SMA horizontal fit. Relative sophistication of the SMA system is also congruent with the more dynamic prospector type strategy, deliberate decisions and above average market orientation. Thus these observations suggest a degree of consistency on both the horizontal and vertical dimensions for the analytics group. The blue chips group manifest low accountant participation in strategy and relatively high to average usage of SMA techniques, thus signifying relatively low horizontal fit. Low participation and average SMA usage also appears unsuited for a prospector type/deliberate/market 
oriented strategy, hence also signifying relatively low vertical fit. The first movers have the highest horizontal fit, as they demonstrate very high accountant strategy participation and the highest SMA usage rates. Their superior SMA systems are also aligned with their high prospector oriented strategy and their high market orientation, signifying high vertical fit. The domestic protectors group displays mid-range levels of SMA usage, and their accountants' participation in strategy is slightly above average, suggesting a degree of horizontal misalignment. While their degree of SMA technique development appears aligned to their average market orientation, this cannot be said with respect to their highly emergent orientation with respect to strategy development. The laggards group exhibits low SMA adoption rates and also low accountant participation in strategy. This suggests high horizontal fit. With respect to strategic choices, laggards are defender type oriented, strategy is somewhat deliberate and the level of market orientation is lower than average. Consistent with the rationale already outlined in this section, the laggards' low SMA system development appears as relatively consistent with its strategy, signifying high vertical fit. Finally, the socialism relics can be interpreted as a more extreme case to the laggards. Hence, the configuration of an underdeveloped SMA system and a defender type, emergent, low market-oriented approach to strategy is again consistent with low SMA system development and low accountant strategy participation.

Table 4 provides a summary of the observations made in this section and relates these to cluster performance. The observed configurations constitute varying degrees of fit and varying levels of performance, however, no strong relation between degree of fit and performance is in evidence. Although the analytics group exhibits a high degree of configurational alignment and a high level of performance, for three groups (i.e. bluechips, laggards and socialism relics) the expected relationship between fit and performance is inverted. Thus, considered holistically, the observations provide only partial support to the proposition that higher internal consistency of strategy-SMA system configurations is associated with higher performance.

Table 4. Summary of the 6 clusters' configurational consistency and performance

\begin{tabular}{lccc}
\hline \multicolumn{1}{c}{ Configuration } & Degree of horizontal fit & Degree of vertical fit & Performance level \\
\hline Analytics & High & High & High \\
Blue chips & Low & Low & High \\
First movers & Highest & High & High non-financial \\
Domestic protectors & Medium & Medium & Moderate \\
Laggards & High & High & Low \\
Socialism relics & Highest & Highest & Lowest \\
\hline
\end{tabular}

\section{Discussion and conclusion}

This is one of the first studies to adopt a configurational perspective with respect to strategic choices, strategic management accounting systems, and performance. The study can be seen to break new ground by examining whether organizationally aligned configurations are associated with higher performance. 
The study provides support for the equifinality proposition that holds that similar levels of performance can be achieved using different strategic and structural alternatives. This finding is consistent with assertions that different strategic types can be effective (Miles and Snow, 1978) which has received prior empirical support (i.e. Bensaou and Venkatraman, 1995; Marlin et al., 2007; Short et al., 2008). It is notable that this finding challenges much traditional mainstream contingency based modelling in management accounting. For example, the management accounting literature provides ample empirical evidence suggesting that a dynamic prospector type strategy is associated with broad scope information systems, such as SMA, and that this combination positively affects performance (i.e. Abernethy and Guthrie, 1994; Cadez and Guilding, 2008; Chong and Chong, 1997). These studies assume that both the relationship between the variables and fit are continuous functions (Gerdin and Greve, 2004). The findings of this study call into question the assumed continuous nature of such relationships, as we have identified three relatively successful configurations which manifest diverse approaches to the prospector/defender philosophy, as well as differing degrees of SMA deployment.

Only limited support is provided for the configurational proposition that internally consistent strategy and SMA system configurations are associated with higher performance. When trying to relate the findings of this study to prior configurational management accounting research, we have little to build on. Our literature search suggests that the only prior study that has attempted a configurational analysis of strategic choices and management accounting practices was conducted by Chenhall and Langfield-Smith (1998), despite this study being theoretically grounded in the contingency framework. Chenhall and Langfield-Smith found that in organizations pursuing similar strategic priorities, performance tends to be higher where management accounting practices are congruent with strategy (i.e., where high vertical fit is achieved).

This somewhat contradictory observation beckons further consideration, especially in connection with the three groups (i.e. blue-chips, laggards and socialism relics), where observations contradicting the proposition were observed. While Miles and Snow (1978) assert that all their proposed strategic types can be effective, this is only true if they are well aligned to the environment encountered (Desarbo et al., 2005) and if the business functions are supportive of the grand strategies selected (Olson et al., 2005; Slater and Olson, 2001). This consideration is particularly pertinent, given the particular context of the country surveyed in this study. Only two decades ago, in the socialist system, all Slovenian companies were production oriented and competitive strategic planning was minimal (Biloslavo and Lynn, 2007). It appears likely that the laggards and socialism relics have been slow to evolve strategies and structures that are appropriately aligned with the radically altered Slovenian commercial context. Olson et al. (2005) provide evidence that a base level of marketing is required in every company to be effective, whereas Desarbo et al. (2006) find that for defenders, marketing and market-linking capabilities are most significantly related to performance, hence implying a potential misalignment of the strategic choices for these two groups. It is also noteworthy that Chenhall and Langfield-Smith (1998) found that the lowest performing configuration attached low emphasis on all strategic priorities and had the least developed management accounting practices. While underdeveloped SMA systems may 
be consistent with strategic corporate inertia, they do not counter the negative implications arising from the pursuit of inappropriate strategies. Ketchen et al. (1993), Ferguson and Ketchen (1999) and Simons (1994) note that this type of misalignment is not uncommon, as evolution from a mis-aligned poor-performing configuration can require strategic and structural change that is time consuming and expensive, thus disparities in fit can be experienced for prolonged periods. Contrasting with the laggards and socialism relics, the blue-chips appear to be pursuing a strategy that is well aligned with the environment. DeSarbo et al. (2006) note, however, that for protectors, only technology capabilities relate significantly to performance, whereas SMA related capabilities, such as IT and management capabilities are not related to performance. This finding suggests that the relatively high performance of this group can be attributed to factors that have not been captured in the current study (i.e. technology capabilities). These factors may well have the capacity to override the apparently inconsistent configuration between SMA systems and strategy.

We also note that ambiguous support for the configurational proposition is not inconsistent with prior configurational studies reported in the management literature. Much of the empirical evidence is equivocal. While many studies detect only weak or no link between organizational configurations and performance (see Ketchen et al., 1997; Short et al., 2008; for a review), Doty et al. (1993), Olson et al. (2005), and Slater and Olson (2001) provide evidence that fit among strategic and structural factors is a predictor of organisational effectiveness.

Although the discussion provided above highlights substantial shortcomings in contingency based modelling (see also Fiss, 2007; Gerdin and Greve, 2004; 2008; Gresov and Drazin, 1997), the contingency paradigm is likely to remain dominant in empirical research concerned with relationships between strategy and management accounting. The reasons for this seem to be many. First, the simultaneous investigation of a variety of variables that characterises the configurational approach inevitably leads to the problem of conflicting contingencies (Doty and Glick, 1994; Fiss, 2007; Gerdin, 2005; Gresov, 1989). This complexity makes interpretation and theory building difficult. Second, Ittner and Larcker (2001) contend that managerial accountants exhibit an innate interest in providing insights with respect to management accounting practices that impact positively on organizational performance, a quest consistent with contingency theory. Third, the simultaneous testing of multiple fits precludes the use of rigorous statistical methods, such as regression analysis or structural equation modelling (Gerdin and Greve, 2004; Fiss, 2007). This is an important consideration, as most strategy-management accounting studies are published in accounting journals which tend to attach a premium to the capacity to exhibit statistical rigour (Lukka, 2010; Malmi, 2010). As a result, the accounting research fraternity has been criticised for its focus on standardized approaches that is induced by career instrumentalism (Hopwood, 2008).

The findings of the reported study should be viewed in the context of its limitations. To start with, it would be misleading and inappropriate to suggest that the range of variables examined are exhaustive. They clearly fall a long way short of fully capturing the complexity of pertinent configurations. Next, significant limitations revolve around 
applicaton of the cluster analytical technique and its reliance on researcher judgement. Determining the number of clusters requires the exercise of some subjectivity, although an attempt was made to mitigate this weakness by deploying a recommended two step clustering approach and a cluster validation procedure (Ketchen and Shook, 1996; Ketchen et al., 1993; Slater and Olson, 2001). Further, cluster analysis does not carry statistical rigour, nor a clear notion of fit. Another problem is the potential for multicollinearity between clustering variables. In this study, the correlations were not excessively high (the highest noted correlation was 0.51 ), hence the decision was taken not to correct for multicollinearity, due to the many pitfalls associated with correctional methods (Ketchen and Shook, 1996). A further shortcoming relates to the use of a single item measure of business strategy. Ittner and Larcker (2001) note that single item measurement is likely to result in measurement error. Another limitation stems from the fact that, with the exception of company size, the study did not examine the potential moderating effects of other environmental and organizational variables.

The most important implication arising from this study, both for practitioners and researchers, concerns the importance of not assuming a singular relationship between strategic choices and management accounting system design. While researchers have previously offered management accounting prescriptions based mainly on vertical unidirectional relationships between individual variables, with this study we raise the notion of how a set of important variables can interact with one another vertically, horizontally, and reciprocally to create an effective organization. The conjecture that there are multiple strategic and structural designs that may prove to be equally effective for a particular context lends support to Fiss' (2007) call for future research to move beyond simple contingency approaches. 


\section{References}

Abernethy, M.A. and Guthrie, C.H. (1994), "An empirical assessment of the "fit" between strategy and management information system design”, Accounting and Finance, Vol. 34, pp. 72-80.

Abernethy, M.A. and Bouwens, J. (2005), "Determinants of accounting innovation implementation", Abacus, Vol. 41, pp. 217-239.

Aver, B. and Cadez, S. (2009), "Management accountants' participation in strategic management processes: a cross industry comparison”, Journal for East European Management Studies, Vol. 14, pp. 310-322.

Biloslavo, R. and Lynn, M. (2007), "Mission statements in Slovene enterprises - Institutional pressures and contextual adaptation”, Management Decision, Vol. 45, pp. 773-788.

Bensaou, M. and Venkatraman, N. (1995), "Configurations of interorganizational relationships: a comparison between U.S. and Japanese automakers", Management Science, Vol. 41, pp. 1471-1492.

Bhimani, A. and Langfield-Smith, K. (2007), "Structure, formality and the importance of financial and non-financial information in strategy development and implementation", Management Accounting Research, Vol. 18, pp. 3-31.

Cadez, S. and Guilding, C. (2008), "An exploratory investigation of an integrated contingency model of strategic management accounting”, Accounting, Organizations and Society, Vol. 33, pp. 836-863.

Carr, C., Kolehmainen, K. and Mitchell, F. (2010), "Strategic investment decision making practices: A contextual approach", Management Accounting Research, Vol. 21, pp. 167-184.

Chenhall, R.H. and Langfield-Smith, K. (1998), "The relationship between strategic priorities, management techniques and management accounting: an empirical investigation using a systems approach", Accounting, Organizations and Society, Vol. 23, pp. 243-264.

Chenhall, R.H. (2003), "Management control systems design within its organizational context: findings from contingency-based research and directions for the future", Accounting, Organizations and Society, Vol. 28, pp. 127-168.

Chong, V.K. and Chong, K.M. (1997), "Strategic choices, Environmental uncertainty and SBU performance: a note on the intervening role of management accounting systems", Accounting and Business Research, Vol. 27, pp. 268-276.

Delery, J.E. and Doty, H.D. (1996), "Modes of theorizing in strategic human resource management: tests of universalistic, contingency, and configurational performance predictions", Academy of Management Journal, Vol. 39, pp. 802-835.

Desarbo, W.S., Di Benedetto, C.A., Song, M. and Sinha, I. (2005), "Revisiting the Miles and Snow strategic framework: uncovering relationships between strategic types, capabilities, environmental uncertainty, and firm performance", Strategic Management Journal, Vol. 26, pp. 47-74.

Desarbo, W.S., Di Benedetto, C.A., Jedidi, K. and Song, M. (2006), "Identifying sources of heterogeneity for empirically deriving strategic types: a constrained finite-mixture structural-equation methodology", Management Science, Vol. 52, pp. 909-924.

Dobni, B. and Luffman, G. (2003), "Determining the scope and impact of market orientation profiles on strategy implementation and performance”, Strategic management Journal, Vol. 24, pp. 577-585.

Doty, H.D., Glick, W.H. and Huber, G.P. (1993), "Fit, equifinality, and organizational effectiveness: a test 
of two configurational theories", Academy of Management Journal, Vol. 36, pp. 1196-1250.

Doty, H.D. and Glick, W.H. (1994), "Typologies as a unique form of theory building: Toward improved understanding and modeling”, Academy of Management Review, Vol. 19, pp. 230-251.

Ferguson, T.D. and Ketchen, D.J. (1999), "Organizational configurations and performance: the role of statistical power in extant research”, Strategic Management Journal, Vol. 20, pp. 385-395.

Ferligoj, A. and Batagelj, V. (1992), "Direct multicriteria clustering algorithms", Journal of Classification, Vol. 9, pp. 43-61.

Fiss, P.C. (2007), “A set-theoretic approach to organizational configurations", Academy of Management Review, Vol. 32, pp. 1180-1198.

Gerdin, J. and Greve, J. (2004). "Forms of contingency fit in management accounting research-a critical review", Accounting, Organizations and Society, Vol. 29, pp. 303-326.

Gerdin, J. (2005), "Management accounting system design in manufacturing departments: an empirical investigation using a multiple contingencies approach", Accounting, Organizations and Society, Vol. 30, pp. 99-126.

Gerdin, J. and Greve, J. (2008), "The appropriateness of statistical methods for testing contingency hypotheses in management accounting research", Accounting, Organizations and Society, Vol. 33, pp. 995-1009.

Green, K. W., Inman R. A. and Birou L. M. (2011), "Impact of JIT-selling strategy on organizational structure”, Industrial Management \& Data Systems, Vol. 111, pp. 63 - 83.

Gresov, C. (1989), "Exploring fit and misfit with multiple contingencies", Administrative Science Quarterly, Vol. 34, pp. 431-453.

Gresov, C. and Drazin, R. (1997), "Equifinality: functional equivalence in organization design", Academy of Management Review, Vol. 22, pp. 403-428.

Guilding, C. (1999), "Competitor-focused accounting: an exploratory note", Accounting, Organizations and Society, Vol. 24, pp. 583-595.

Guilding, C., Cravens, K.S. and Tayles, M. (2000), “An international comparison of strategic management accounting practices”, Management Accounting Research, Vol. 11, pp. 113-135.

Guilding, C. and McManus, L. (2002), "The incidence, perceived merit and antecedents of customer accounting: an exploratory note", Accounting, Organizations and Society, Vol. 27, pp. 45-59.

Hair, J.F., Anderson, R.E., Tatham, R.L. and Black, W.C. (1998), Multivariate data analysis (5th ed.). Prentice Hall, Upper Saddle River.

Hammad, S. A., Jusoh, R. and Yeen Nee Oon E. (2010). "Management accounting system for hospitals: a research framework”, Industrial Management \& Data Systems, Vol. 110, pp. 762-784.

Hopwood, A. (2008), "Changing pressures on the research process: on trying to research in an age when curiosity is not enough", European Accounting Review, Vol. 17, pp. 87-96.

Hoque, Z. (2003), Strategic management accounting (2nd ed.). Pearson, Frenchs Forest.

Hoque, Z. and James, W. (2000), "Linking balanced scorecard measures to size and market factors: impact on organizational performance". Journal of Management Accounting Research, Vol. 12, pp. 1-17. 
Hult, G.T.M., Ketchen, D.J. and Slater, S.F. (2005), "Market orientation and performance: an integration of disparate approaches”, Strategic Management Journal, Vol. 26, pp. 1173-1181.

Ittner, C.D. and Larcker, D.F. (2001), "Assessing empirical research in managerial accounting: a valuebased management perspective", Journal of Accounting and Economics, Vol. 32, pp. 349-410.

Jung, Y., Park, H., Du, D. and Drake, B.L: (2003), “A decision criterion of the optimal number of clusters in hierarchical clustering”, Journal of Global Optimization, Vol. 25, pp. 91-111.

Ketchen, D.J., Thomas, J.B. and Snow, C.C. (1993), "Organizational configurations and performance: a comparison of theoretical approaches”, Academy of Management Journal, Vol. 36, pp. 1278-1313.

Ketchen, D.J. and Shook, C. (1996). "The application of cluster analysis in strategic management research: an analysis and critique”, Strategic Management Journal, Vol. 17, pp. 441-458.

Ketchen, D.J., Combs, J.G., Russel, C.J., Shook, C., Dean, M.A., Runge, J., Lohrke, F.T., Naumann, S.E., Haptonstahl, D.E., Baker, R., Beckstein, B.A., Handler, C., Honig, H. and Lamoreux, S. (1997), "Organizational configurations and performance: a meta-analysis", Academy of Management Journal, Vol. 40, pp. 223-240.

Langfield-Smith, K. (1997), "Management control systems and strategy: a critical review", Accounting, Organizations and Society, Vol. 22, pp. 207-232.

Langfield-Smith, K. (2008), "Strategic management accounting: how far have we come in 25 years?", Accounting, Auditing \& Accountability Journal, Vol. 21, pp. 204-228.

Luft, J. and Shields, M.D. (2003), "Mapping management accounting: graphics and guidelines for theoryconsistent empirical research", Accounting, Organizations and Society, Vol. 28, pp. 169-249.

Lukka, K. (2010), “The roles and effects of paradigms in accounting research", Management Accounting Research, Vol. 21, pp. 110-115.

Malmi, T. and Brown, D.A. (2008), "Management control systems as a package-Opportunities, challenges and research directions", Management Accounting Research, Vol. 19, pp. 287-300.

Malmi, T. (2010), "Reflections on paradigms in action in accounting research", Management Accounting Research, Vol. 21, pp. 121-124.

Marlin, D., Ketchen, D.J. and Lamont, B. (2007), "Equifinality and the strategic groups - performance relationship”, Journal of Managerial Issues, Vol. XIX, pp. 208-232.

Miles, R.E. and Snow, C.C. (1978). Organizational strategy, structure and process, McGraw-Hill, New York.

Mintzberg, H. and Waters, J. A. (1985), “Of strategies, deliberate and emergent”, Strategic Management Journal, Vol. 6, pp. 257-272.

Mintzberg, H. (1987), “Crafting strategy”, Harvard Business Review, Vol. 65, pp. 66-75.

Naranjo-Gil, D. and Hartmann, F. (2007), "Management accounting systems, top management team heterogeneity and strategic change", Accounting, Organizations and Society, Vol. 32, pp. 735-756.

Narver, J.C. and Slater, S.F. (1990), "The effect of market orientation on business profitability", Journal of Marketing, Vol. 54, pp. 20-35. 
Olson, E.M., Slater, S.F. and Hult, T.M. (2005), "The performance implications of fit among business strategy, marketing organizations structure, and strategic behaviour”, Journal of Marketing, Vol. 69, pp. 49-65.

Payne, G.T. (2006), "Examining configurations and firm performance in a suboptimal equifinality context”, Organization science, Vol. 17, pp. 756-770.

Roslender, R. and Hart, S. (2003), "In search of strategic management accounting: theoretical and field study perspectives", Management Accounting Research, Vol. 14, pp. 255-279.

Short, J.C., Payne G.T., and Ketchen D.J. (2008), "Research on organizational configurations: past accomplishments and future challenges", Journal of Management, Vol. 34, pp. 1053-1080.

Shortell, S.M. and Zajac, E.J. (1990), “Perceptual and archival measures of Miles and Snow's strategic types: a comprehensive assessment of reliability and validity", Academy of Management Journal, Vol. 33, pp. 817-832.

Simons, R. (1987), "Accounting control systems and business strategy: an empirical analysis", Accounting, Organizations and Society, Vol. 12, pp. 357-374.

Simons, R. (1994), "How top managers use control systems as levers of strategic renewal", Strategic Management Journal, Vol. 15, pp. 169-189.

Slater, S.F. and Olson, E.M. (2001), "Marketing's contribution to the implementation of business strategy: an empirical analysis", Strategic Management Journal, Vol. 22, pp. 1055-1067.

Trkman, P. (2010), “The critical success factors of business process management”, International Journal of Information Management, Vol. 30, 125-134.

Trkman, P., McKormack, K., de Oliveira, M.P.V. and Ladeira M.B. (2010), "The impact of business analytics on supply chain performance", Decision Support Systems, Vol. 49, pp. 318-327.

Tucker, B., Thorne, H. and Gurd, B. (2009), "Management control systems and strategy: What's been happening?", Journal of Accounting Literature, Vol. 28, pp. 123-163.

Wooldridge, B. and Floyd, S.W. (1990), “The strategy process, middle management involvement and organizational performance”, Strategic Management Journal, Vol. 11, pp. 231-241.

Zelbst, P., Green, K. W., Abshire, R. D. and Sower, V. E. (2010), "Relationships among market orientation, JIT, TQM, and agility", Industrial Management \& Data Systems, Vol. 110, pp. 637-658.

Yi, M. and Tayles, M. (2009), "On the emergence of strategic management accounting: an institutional perspective”, Accounting and Business Research, Vol. 39, pp. 473-495. 